\title{
Microwave Plasma Assisted Synthesis of Single Crystal Diamond at High Pressures and High Power Densities
}

\author{
J. Lu a, Y. Gu a, D. K. Reinhard a, b, T. A. Grotjohn a, b, and J. Asmussen a, b \\ a Michigan State University, Department of Electrical \& Computer Engineering, East Lansing, MI 48824 \\ b Fraunhofer USA, Center for Coatings and Laser Applications, East Lansing, MI 48824
}

\section{ABSTRACT}

Current microwave plasma assisted chemical vapor deposition (MPACVD) diamond synthesis theory suggests that CVD synthesized diamond quality and growth rates can be improved by using high power density microwave discharges operating at pressures above 160 Torr [1]. Thus we are experimentally exploring single crystal diamond (SCD) synthesis under high pressure and high power density conditions that take advantage of the improved deposition chemistry and physics that may exist in the high pressure (180-300 Torr) regime. Here in this poster paper the experimental results for SCD synthesis are presented using a recently improved 2.45 GHz microwave plasma assisted CVD reactor design [2].

The SCD synthesis was carried out using $\mathrm{H}_{2} / \mathrm{CH}_{4}$ input gas chemistries over the 180-300 Torr regime. SCD growth rates versus pressure, input gas chemistry (with and without $\mathrm{N}_{2}$ addition), and substrate temperature are presented, and output SCD quality was evaluated by Micro-Raman, IR-UV transmission spectrometry and SIMS analysis. SCD growth rates increase as pressure, methane concentration and discharge power density increase. Linear growth rates of $70-80 \mathrm{micron} / \mathrm{hr}$ are achieved without $\mathrm{N}_{2}$ addition. SCD growth rates additionally increase with small amounts of $\mathrm{N}_{2}$ additions (10-200 ppm) to the feed gas. Under similar growth conditions, i.e. temperature, methane concentration, etc., growth rates increase faster vs. $\mathrm{N}_{2}$ addition at higher pressures than at lower pressures. A SCD growth window was observed between $950-1300{ }^{\circ} \mathrm{C}$, the details of which have not been published by other investigators up to now. Micro-Raman spectroscopy, IR-UV transmission spectrometry and SIMS measurements showed that the synthesized SCD was of excellent quality (type IIa, gem quality or better) within the growth window of 1030 $-1250{ }^{\circ} \mathrm{C}$ with high growth rates of $40-45 \mathrm{micron} / \mathrm{hr}$.

\section{REACTOR DESIGNS}

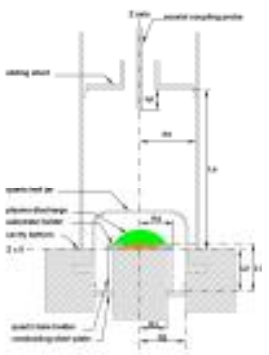

Reactor A

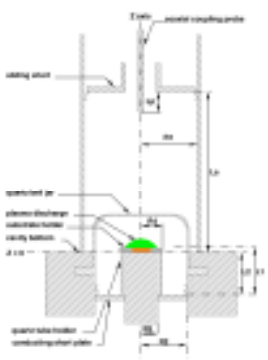

Reactor B

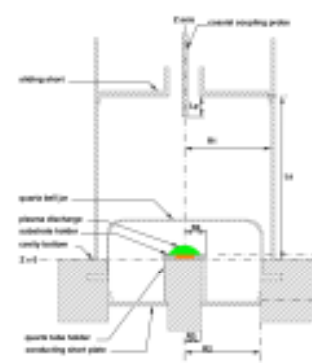

Reactor C [3]

\section{SUBSTRATE HOLDER DESIGN}

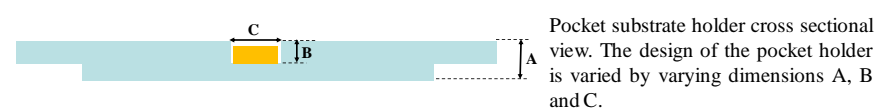

\section{EXPERIMENTAL VARIABLES}

q Independent Process Variables

B Pressure: 160 - 300 Torr

B Absorbed power: $1.4-2.1 \mathrm{~kW}$

Gas feed composition: variable $\mathrm{CH}_{4} / \mathrm{H}_{2}=3-9 \%$

Total gas flow rate constant $\sim 400 \mathrm{sccm}$

Input gas purity: $6 \mathrm{~N}-\mathrm{H}_{2} ; 5.5 \mathrm{~N}-\mathrm{CH}_{4}$

Deposition time: 6 - 24 hours

Substrate type: $3.5 \times 3.5 \mathrm{~mm}^{2}$ HPHT diamond substrates

q Internal Variables

B Substrate temperature (Ts): 900-1400 C

B Plasma volume: $4-10 \mathrm{~cm}^{3}$

B Absorbed power density $\mathrm{P}_{\text {abs }} /$ plasma volume:

$200-650 \mathrm{~W} / \mathrm{cm}^{3}$

\section{REFERENCES}

[1] D. G. Goodwin, J. Appl. Phys. 74, 6888 (1993)

[1] D. G. Goodwin, J. Appl. Phys. 74, 6888 (1993).
[2] K. W. Hemawan, et al., Diamond and Related Materials, 19, 1446-1452 (2010).

[3] Y. Gu, et al., $2^{\text {nd }}$ MIPSE (2011).

\section{EXPERIMENTAL RESULTS}

SCD synthesis is a multi-variable optimization problem - when holding substrate size and flow rate ( $400 \mathrm{SCCM})$ constant the hold major vabsere, an reactor design. A multi-dimens different reactor performance.
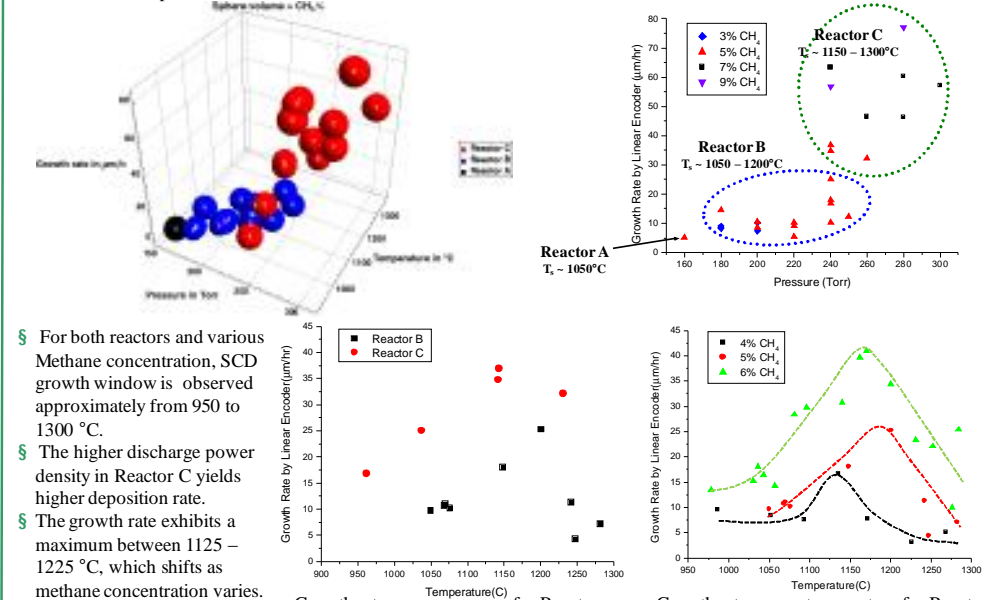
methane concentration varis.

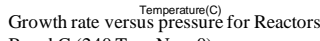
$\mathrm{B}$ and C ( 240 Torr, $\left.\mathrm{N}_{2}=0\right)$

SCD growth rates increase with $\mathrm{N}_{2}$ addition to the feed gas. Under similar growth conditions, growth rates increase faster at higher pressures than at lower pressures respect to $\mathrm{N}_{2}$ concentration.

B The Raman FWHM and N content by SIMS of the synthesized SCD both increase with $\mathrm{N}_{2}$ addition to the feed gas.

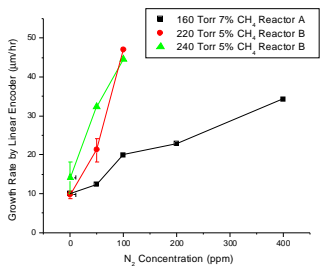
Growth rate versus temperature for Reacto B $\left(240\right.$ Torr, $\left.\mathrm{N}_{2}=0\right)$

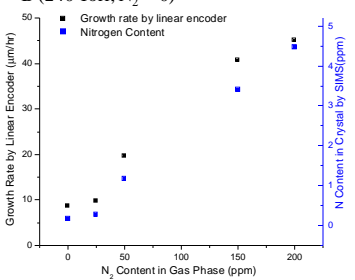

Growth rate versus $\mathrm{N}_{2}$ concentration Growth rate \& $\mathrm{N}$ content versus $\mathrm{N}_{2}$ concentration

\section{DIAMOND QUALITY}
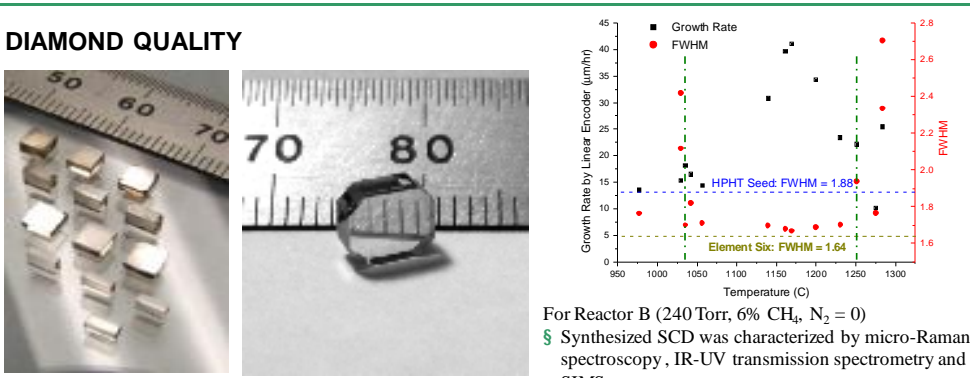

For Reactor B ( 240 Torr, $6 \% \mathrm{CH}_{4}, \mathrm{~N}_{2}=0$ )

Synthesized SCD was characterized by micro-Raman spectroscopy, IR-UV transmission spectrometry and SIMS. B Thick diamond plates were fabricated by removing the SCD B A good quality SCD growth window was observed
layer from the seed by laser cutting.
between $1030-1250^{\circ} \mathrm{C}$. layer from the seed by laser cutting.

B The plates were mechanically polished and the edges were

The plates were

B The large size SCD plate on the right is near colorless, type IIa, the synthesized SCD. IR-UV transmission 1.1 carat measurement also indicates type IIa diamond.

\section{SUMMARY}

At high process pressures of 180-300 Torr,

q SCD growth rates increase as pressure, methane concentration and discharge power density increase and linear growth rates of $70-80$ microns $/ \mathrm{hr}$ are possible without $\mathrm{N}_{2}$ addition.

q A SCD growth window was observed between $950-1300{ }^{\circ} \mathrm{C}$, the details of which have not been published by other investigators up to now.

q Micro-Raman spectroscopy, IR-UV transmission spectrometry and SIMS measurements showed that the synthesized SCD was of excellent quality (type IIa: gem quality or better) within the growth window of $1030-1250{ }^{\circ} \mathrm{C}$ with high growth rate.

q SCD growth rates increase with $\mathrm{N} 2$ addition to the feed gas. Under similar growth conditions, i.e. temperature, methane concentration, etc., growth rates increase faster at higher pressures than at lower pressures.

q The trends of the results of diamond quality and growth rate are consistent with the predictions from the simple theory of diamond growth and quality from Harris and Goodwin [1]. 